\title{
Treatment of Rheumatoid Arthritis with Traditional Chinese Medicine
}

\author{
Wen-Yuan Lee, ${ }^{1,2,3}$ Hsin-Yi Chen, ${ }^{2}$ Kuan-Chung Chen, ${ }^{4}$ and Calvin Yu-Chian Chen ${ }^{1,2}$ \\ ${ }^{1}$ School of Medicine, College of Medicine, China Medical University, Taichung 40402, Taiwan \\ 2 Department of Biomedical Informatics, Asia University, Taichung 41354, Taiwan \\ ${ }^{3}$ Department of Neurosurgery, China Medical University Hospital, Taichung 40447, Taiwan \\ ${ }^{4}$ School of Pharmacy, China Medical University, Taichung 40402, Taiwan \\ Correspondence should be addressed to Calvin Yu-Chian Chen; ycc929@MIT.edu
}

Received 14 February 2014; Revised 5 March 2014; Accepted 5 March 2014; Published 4 June 2014

Academic Editor: Chung Y. Hsu

Copyright (c) 2014 Wen-Yuan Lee et al. This is an open access article distributed under the Creative Commons Attribution License, which permits unrestricted use, distribution, and reproduction in any medium, provided the original work is properly cited.

\begin{abstract}
Rheumatoid arthritis (RA) is a chronic inflammatory disease that will affect quality of life and, working efficiency, and produce negative thoughts for patients. Current therapy of RA is treated with disease-modifying antirheumatic drugs (DMARDs). Although most of these treatment methods are effective, most patients still have a pleasant experience either due to poor efficacy or side effects or both. Interleukin-6 receptor (IL6R) is important in the pathogenesis of RA. In this study, we would like to detect the potential candidates which inhibit IL6R against RA from traditional Chinese medicine (TCM). We use TCM compounds from the TCM Database@Taiwan for virtually screening the potential IL6R inhibitors. The TCM candidate compound, calycosin, has potent binding affinity with IL6R protein. The molecular dynamics simulation was employed to validate the stability of interaction in the protein complex with calycosin. The analysis indicates that protein complex with calycosin is more stable. In addition, calycosin is known to be one of the components of Angelica sinensis, which has been indicated to have an important role in the treatment of rheumatoid arthritis. Therefore, calycosin is a potential candidate as lead compounds for further study in drug development process with IL6R protein against rheumatoid arthritis.
\end{abstract}

\section{Introduction}

According to WHO statistics, 1-2 per two hundred people suffer from rheumatoid arthritis in 2010 [1]. Half of the adults who have been diagnosed with an autoimmune disease in the past ten years are not in full-time work. Autoimmune disease is a form of connective tissue disease that mainly encroaches upon the epitenon synovium and joint. This inflammation can cause joint deformation leading to disability, and the patient will lose some of the joint activity due of joint pain and wear. This inflammation will systematically affect other extra articular tissues, including vascular, skin, muscles, lungs, and heart. People with rheumatoid arthritis may suffer an increase in myocardial infarction (heart attack), the risk of atherosclerosis, and stroke $[2,3]$. Other complications could include left heart failure, pericarditis, endocarditis, cardiac valve inflammation, and fibrosis [4].
Nowadays, as increasing number of mechanisms of diseases have been identified [5-10], the researchers detect more and more potential target proteins against each disease, which are useful for drug design [11-15]. Interleukin-6 receptor (IL6R) is important in the pathogenesis of rheumatoid arthritis (RA) [16, 17]. It is an autoimmune disease which principally attacks synovial joints and causes long-term chronic inflammation. Many research results indicate that RA may be an inherent immune response [18]. Half of the risk of RA is thought to be genetic [1] and it has been found to be strongly associated with the major histocompatibility complex (MHC) antigen HLA-DR4 (specifically 0404 and DR0401) and the expression of genes PTPN22 and PADI4. Family history is therefore thought to be an important risk factor $[19,20]$ as inheritance of the PTPN22 gene has been shown to double the vulnerability to RA. It is notable that PADI4 has been identified as the main 
TABLE 1: Dock score and other criteria used in screening the TCM database for the top twenty candidates.

\begin{tabular}{|c|c|c|c|c|c|c|}
\hline Name & Dock score & -PLP1 & -PLP2 & H-bond forming residues & H-bond quantity & Pi forming residues \\
\hline Calycosin & 43.247 & 56.29 & 54.8 & Glu144, Gln147, Ala160 & 3 & GLN158 \\
\hline Valerophenone-o-carboxylic_acid & 42.473 & 35.29 & 34.33 & Ala160 & 2 & - \\
\hline Senkyunolide_D & 41.848 & 39.67 & 41.1 & Glu144 & 1 & - \\
\hline p-Hydroxyphenethyl_trans-ferulate & 41.789 & 44.6 & 43.56 & Glu144 & 1 & - \\
\hline Coniferyl_ferulate & 41.717 & 54.16 & 59 & Asn110, Glu144, Gln147, Gln158 & 5 & - \\
\hline Riligustilide & 41.56 & 48.51 & 45.81 & - & 0 & - \\
\hline Ferulic_acid & 41.345 & 48.61 & 46 & Glu144, Ala160 & 2 & - \\
\hline Angeliferulate & 40.976 & 46.41 & 40.02 & Gln147, Gln158 & 3 & - \\
\hline Sinaspirolide & 40.283 & 45.76 & 42.57 & - & 0 & - \\
\hline Senkyunolide_P & 40.067 & 46.2 & 41.59 & Asn110 & 1 & - \\
\hline Angelicide & 39.634 & 43.26 & 43.72 & Asn110 & 1 & - \\
\hline Senkyunolide_H & 39.53 & 46.55 & 41.92 & Glu144, Ala160 & 5 & - \\
\hline Senkyunolide-I & 39.471 & 34.44 & 33.41 & Glu144, Ala160 & 3 & - \\
\hline 6_7-Ditydroxyligustide & 38.932 & 48.1 & 50.08 & Glu144, Gln147, Gln158 & 4 & - \\
\hline Vanillic_acid & 38.163 & 36.88 & 34.7 & Glu144, Gln158 & 2 & - \\
\hline Ononin & 38.015 & 23.01 & 25.02 & Glu144 & 2 & - \\
\hline Senkyunolide_I & 37.198 & 29.15 & 34.73 & Glu144, Ala160 & 3 & - \\
\hline 3-Butylidene-4-hydro-phthalide & 36.452 & 30.55 & 29.62 & Asn110, Glu144 & 2 & - \\
\hline Senkyunolide_F & 35.047 & 30.92 & 36.36 & Glu144, Ala160 & 2 & - \\
\hline Formononetin & 34.358 & 53.75 & 50.82 & Aln147 & 1 & Gln158 \\
\hline
\end{tabular}

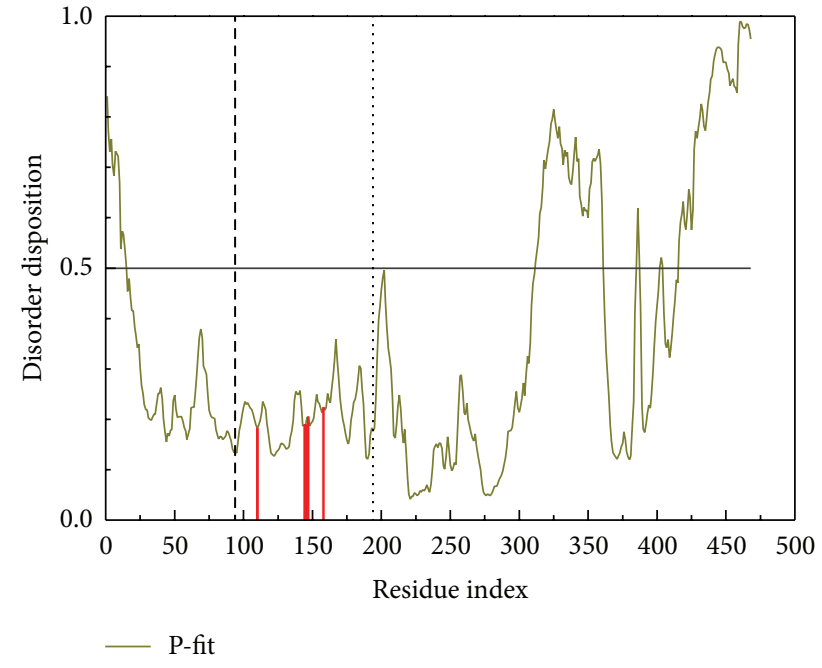

FIGURE 1: Disordered disposition predicted by PONDR-Fit with the key residues (red line).

risk factor in people of Asian descent [12]. First-degree relative prevalence rate is $2-3 \%$, and the concordance of the disease in monozygotic twins is in the region of $15-20 \%$ $[21,22]$. Smoking is the most significant nongenetic risk factor in the development of the disease [1], and statistical data indicate that smokers are up to three times more likely to develop RA than nonsmokers, especially in men [23]. There is some statistical evidence that moderate alcohol consumption may have a protective value. [24]. Vitamin D deficiency is common in rheumatoid arthritis cases and may have a causal<smiles>COc1ccc(-c2coc3cc(O)ccc3c2=O)cc1O</smiles>

FIGURE 2: The chemical structure of calycosin.

association [25]. Some trials have found that a vitamin D supplement can reduce the risk of RA, while others have not [25].

A study by Mayo Clinic in 2005 indicated that rheumatoid arthritis patients suffered from more than double the risk of heart disease than the general population [26], independent of other risk factors, such as alcoholism, diabetes, high cholesterol, body mass index, and elevated blood pressure. RA mechanisms leading to increased risk are unclear, but the presence of chronic inflammation has been proposed as a contributing factor [27]. More and more effective treatments of protein diseases are being discovered [6, 8, 28-32], and treatments involving traditional Chinese medicine (TCM) methods are also attracting much attention; therefore, potential lead compounds are expected from investigations $[28,33-$ 40].

We used computer-aided virtual drug screening [41] with data from the traditional Chinese medicine Database@ Taiwan (http://tcm.cmu.edu.tw/) [42] for the investigation of docking simulation and employed molecular dynamics for the investigation of changes under the static and dynamic 


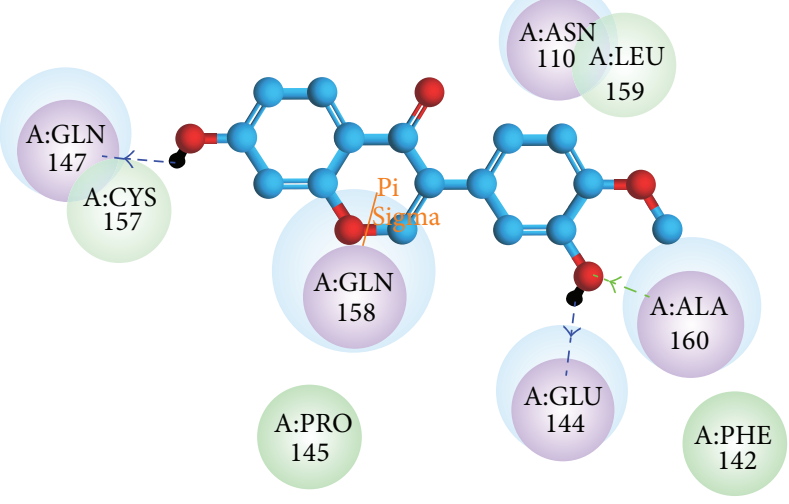

Calycosin

FIGURE 3: Docking pose of candidate compound in IL6R binding site. Hydrogen bonds are expressed in green and blue dotted lines. $\pi$ bond is shown with an orange line.

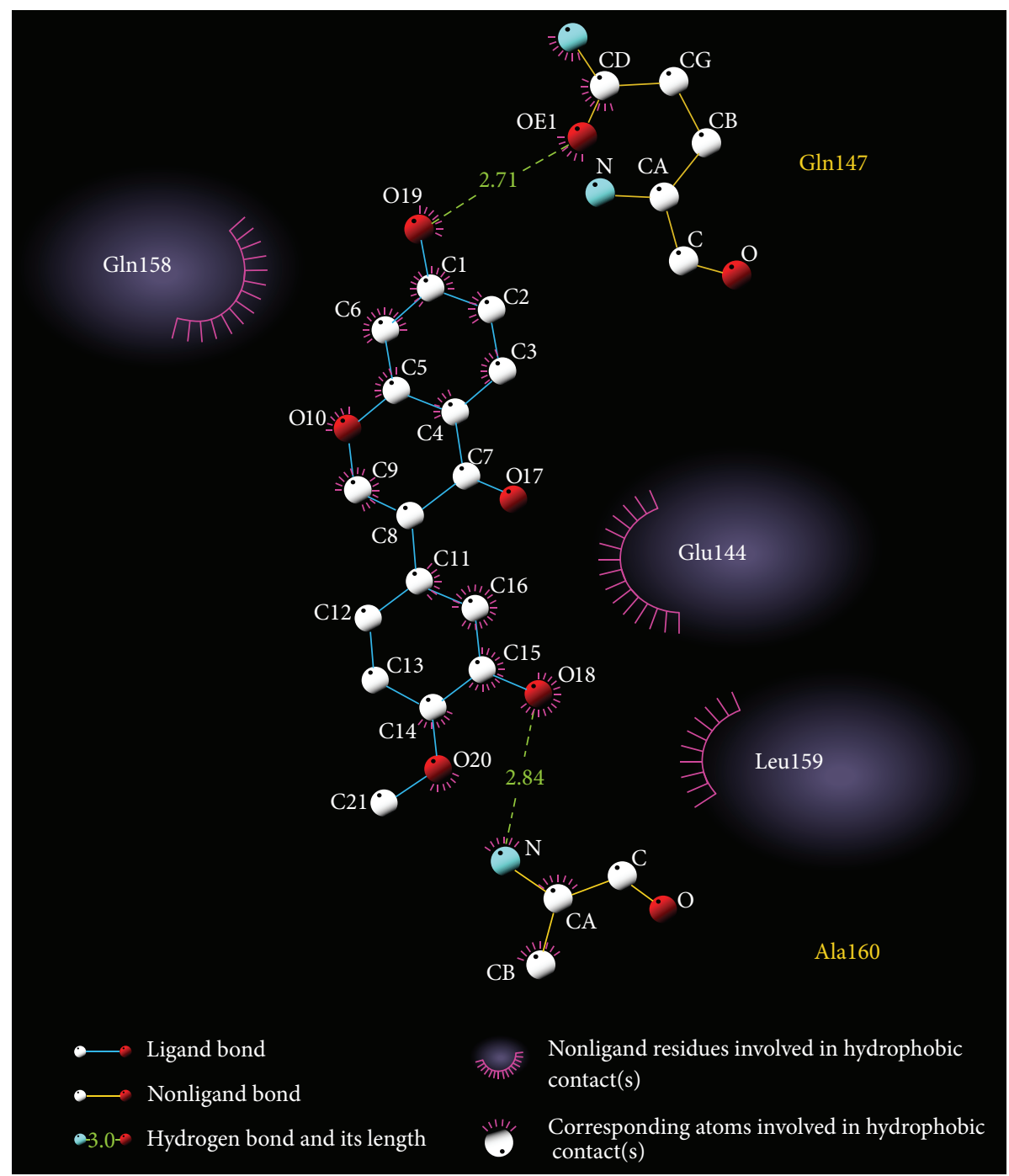

FIGURE 4: Docking pose of candidate compound in IL6R binding site with hydrophobic contacts. 


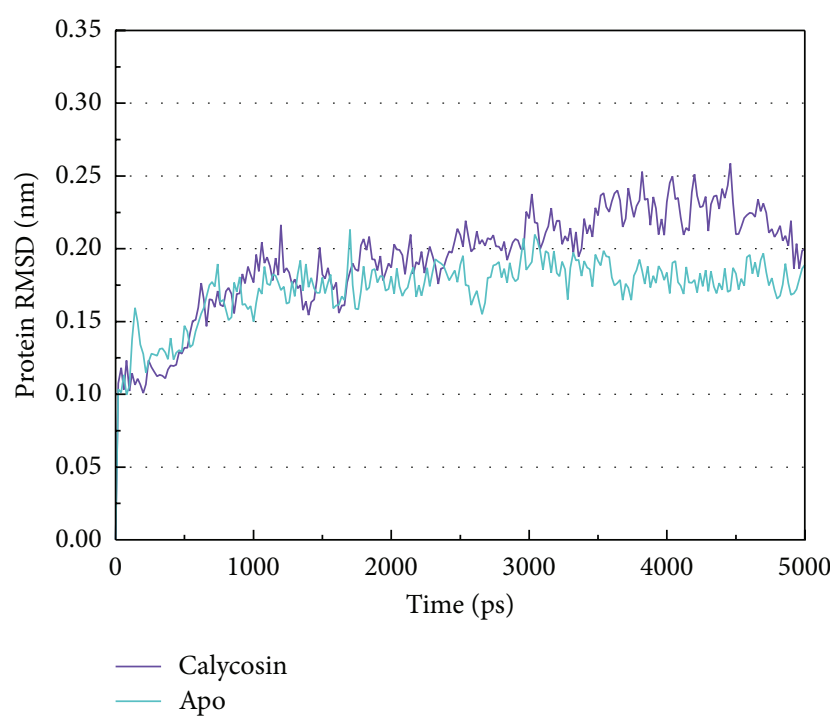

(a)

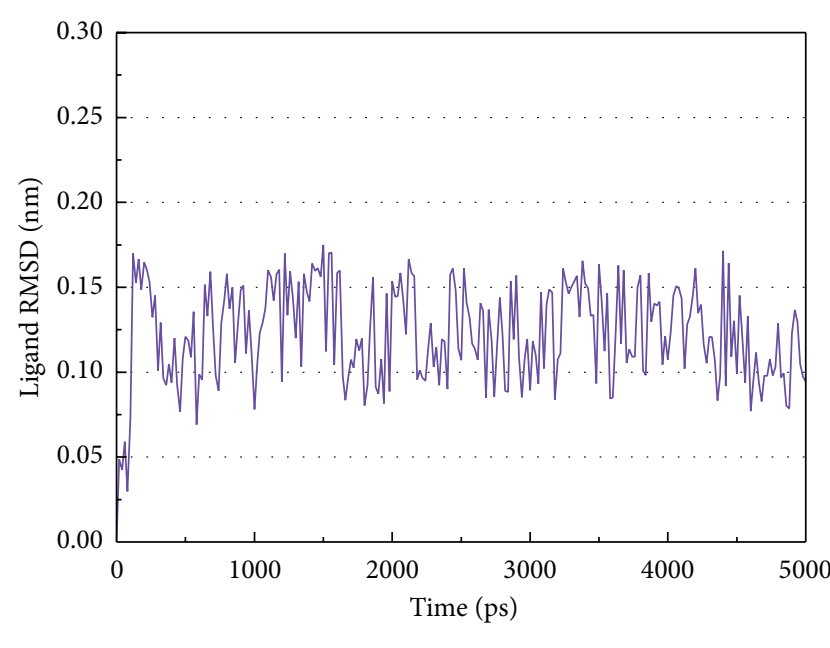

- Calycosin

(b)

FIGURE 5: RMSD of protein and calycosin.

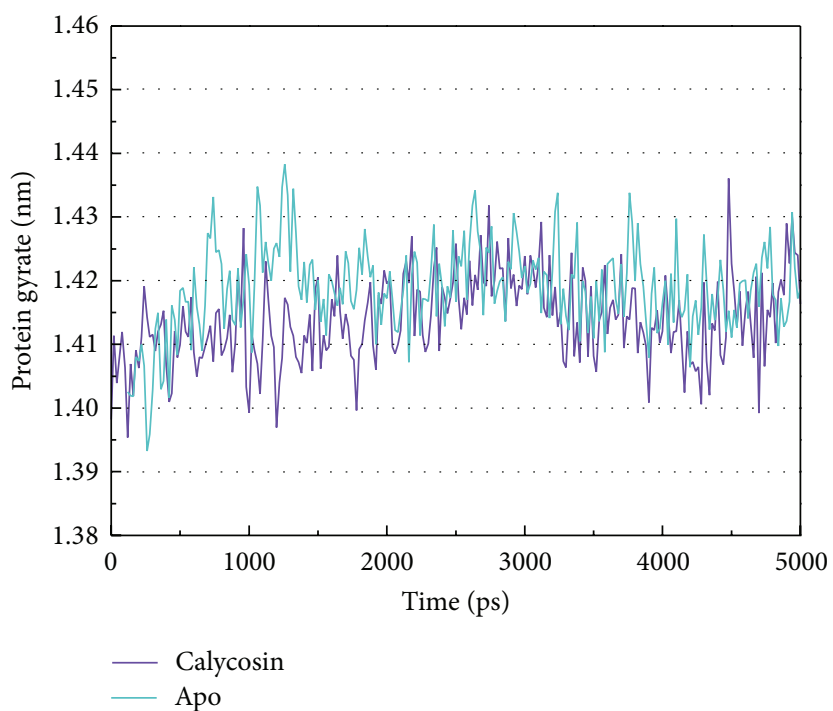

(a)

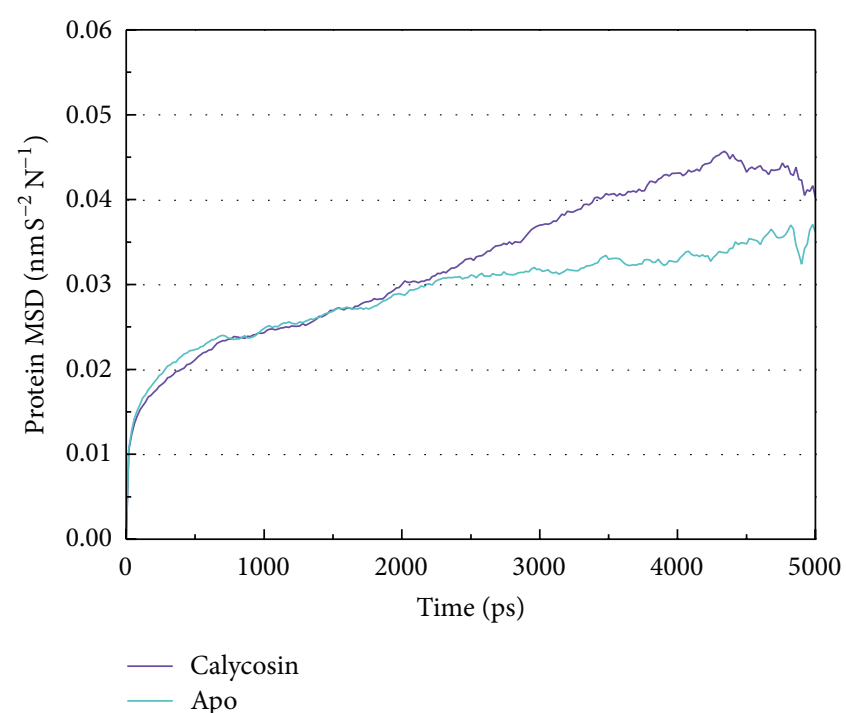

(b)

FIGURE 6: Analysis of MD trajectories generated by Gromacs. (a) Gyrate and (b) mean square deviation (MSD).

conditions to determine natural, effective lead compounds with fewer putative side effects.

\section{Materials and Methods}

2.1. Docking and Candidate Screening. The structure of interleukin-6 receptor (IL6R) was derived from human IL6R kinase from the Protein Data Bank (PDB ID: 1N26) [43]. According to UniProt (P08887), the crystal structure of the binding site is located in residues 94-194. We used the Database of Protein Disorder to verify the stability of the structure with the sequence of crystal structure [44].
The investigation is based on Discovery Studio 2.5.5 LigandFit molecular docking method. The small molecules from TCM database could be used to find suitable candidates for the IL6R receptor. All the traditional Chinese medicine small molecules used for screening had been filtered by Lipinski's rule of five $[45,46]$ and the properties of absorption, distribution, metabolism, excretion, and toxicity (ADMET) [47] in DS 2.5 to rule out potentially toxic derivatives. The binding site was defined by the cocrystallized ligand location in the crystalline structure. All the small molecules for molecular docking were minimized with the smart minimizer setting under the force field of CHARMM [48]. The results of 


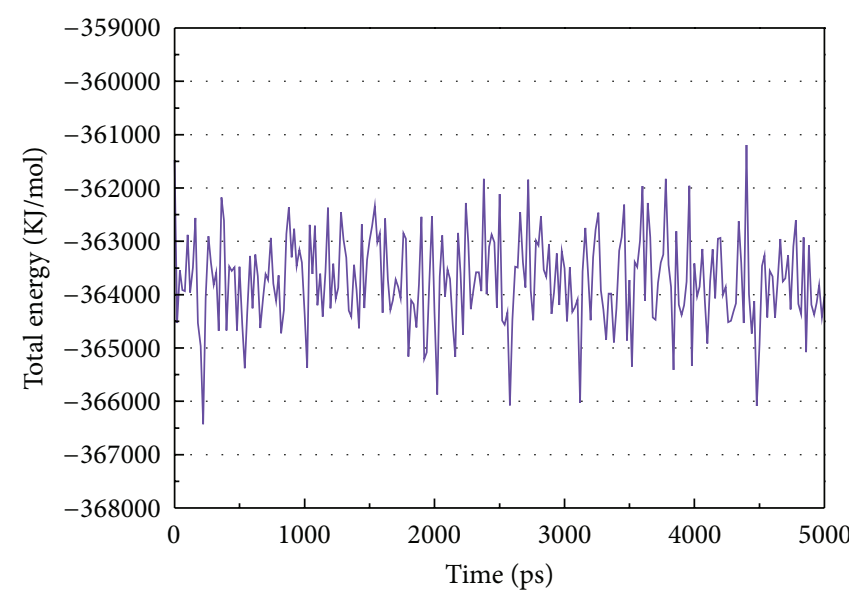

(a)

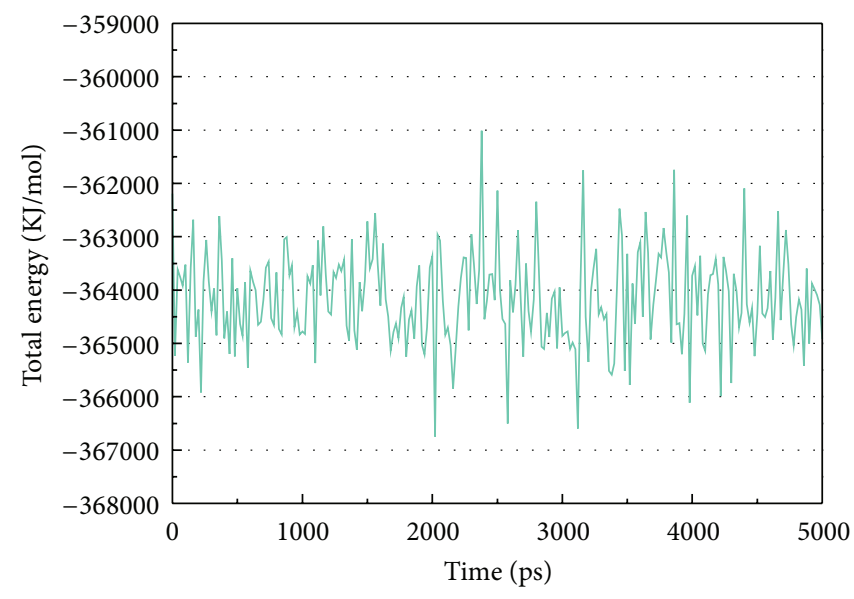

(b)

FIGURE 7: Analysis of transport pathways for (a) protein complex with calycosin and (b) apoprotein.

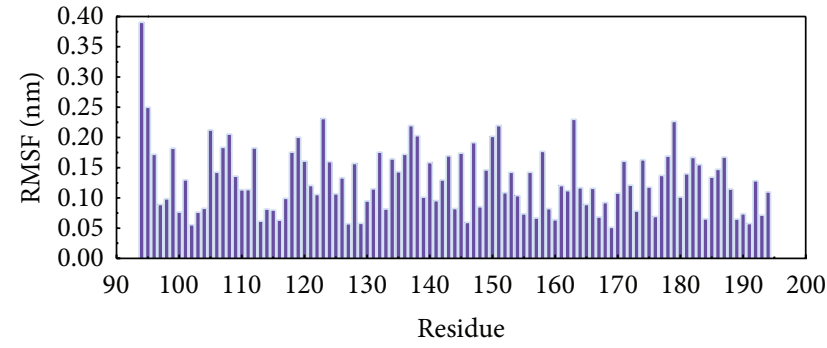

Calycosin

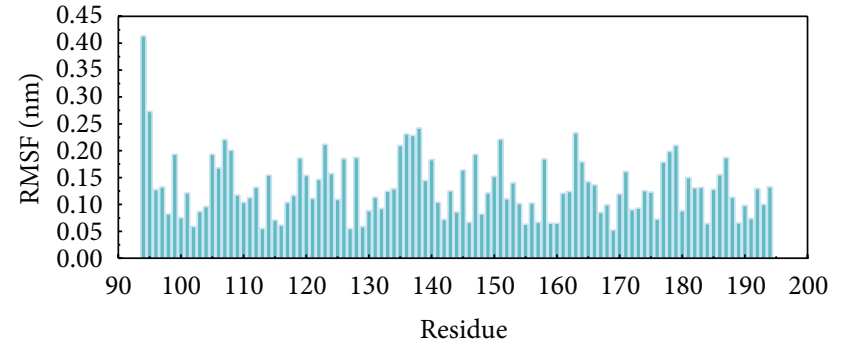

Apo

(a)

(b)

FIGURE 8: RMSF for residues in (a) protein complexes with calycosin and (b) apoprotein.

molecular docking are sorted by Dock score, -PLP1, -PLP2, $\mathrm{H}$-bond forming residues, and $\mathrm{H}$-bond quantity. Pi forming residues were also selected from the top twenty.

2.2. Molecular Dynamics (MD) Simulation. The stability of protein-ligand complex with candidate compounds was validated using molecular dynamics simulation by GROMACS 4.5.5 [49]. The production of MD simulation time was $5 \mathrm{~ns}$. The GROMACS tool provides an analysis of the MD trajectories. The g_rms program was used to compare structures by calculating the root mean square deviation (RMSD) [50] to observe the changes of the overall structure in the dynamic simulation process compared to a reference structure. The g-gyrate program was used for calculation of the radius of gyration of atomic groups about the $x$-axis, $y$-axis, and $z$ axis, as a function of time. The g_msd program was used to analyze the mean square displacement of proteins, and the g_energy program was used to analyze the potential energy, total energy, kinetic energy, temperature, volume, density, pressure change of $\mathrm{pV}$, and enthalpy. The g_rmsf program was used to determine the flexibility level of a region of a protein by analyzing the root mean square fluctuation (RMSF) of each amino acid. In this study, we also analyze the vector distribution diagrams of eigenvector, distance analysis of hydrogen bond, structure clustering, variation of secondary structure, and Mdmat analysis. In addition, the program, CAVER 3.0 [51], was also used to calculate the import and export pathways for the compound. The CAVER program is based on the Dynamic Map Ensemble (DyME) application program. Dynamic proteins in DyME can be constructed from many different configurations of the polymer. This method calculates the free space of protein using a Voronoi diagram, which is presumably the pathway of a small molecule.

\section{Results and Discussion}

3.1. Docking and Candidate Screening. Figure 1 shows the results of verification from PONDR-Fit software and the position of important amino acids. As all the important residues in the binding domain are located below the standard line at 0.5 , thus the crystalline structure is stable for docking simulation. According to the experimental results (Table 1), the Dock score, -PLP1, -PLP2, H-bond forming residues, $\mathrm{H}$-bond quantity, and $\mathrm{Pi}$ forming residues are used to rank the top twenty candidates. Calycosin, the top 

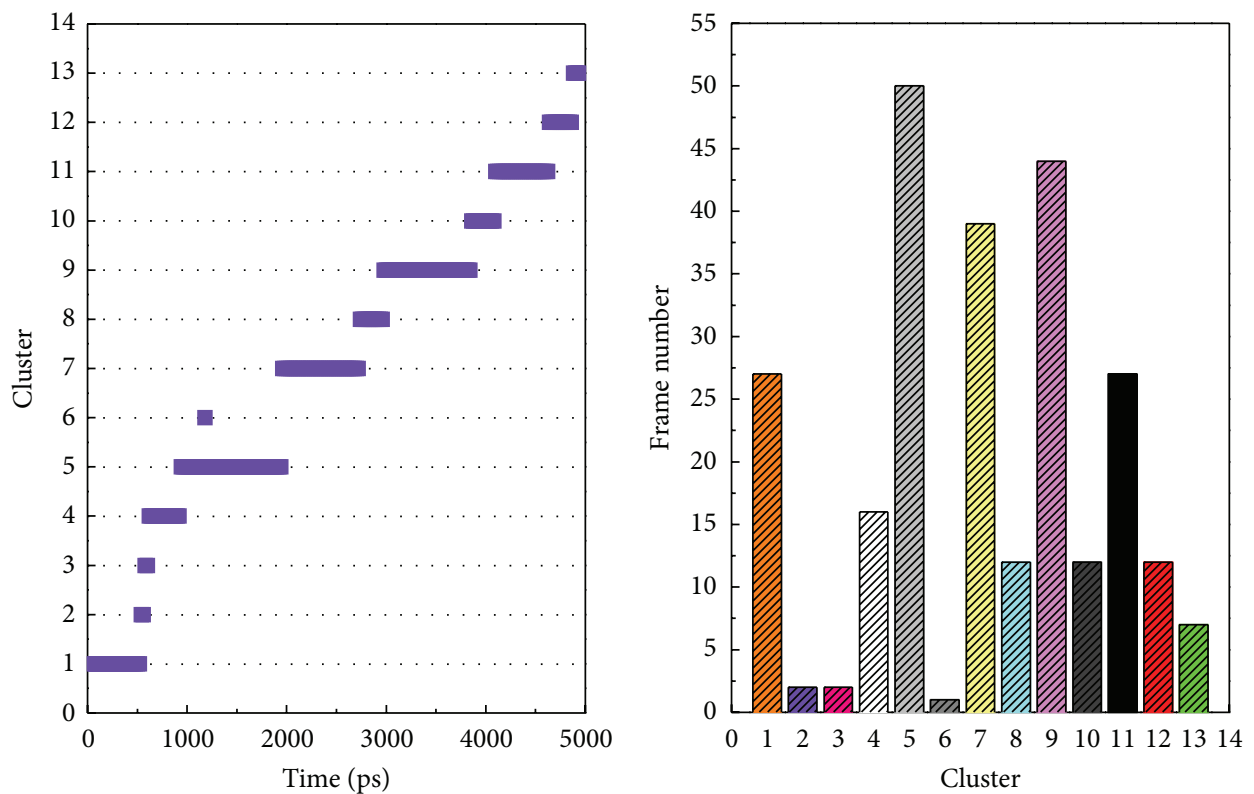

(a)
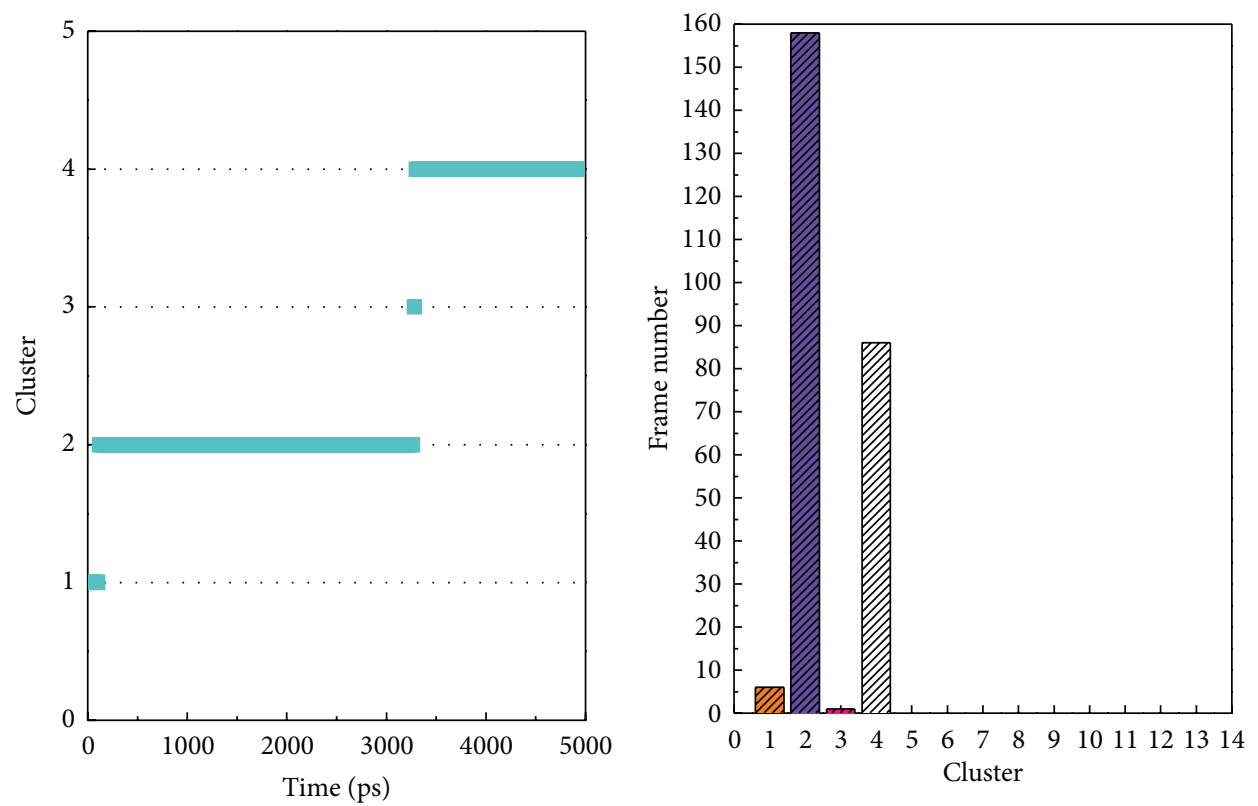

(b)

FIGURE 9: Cluster trend of (a) protein complexes with calycosin (cutoff: $0.142 \mathrm{~nm}$ ) and (b) apoprotein (cutoff: $0.145 \mathrm{~nm}$ ).

candidate, is used for further investigation in this paper. In addition, the apoprotein is used as a control.

Recently, plant based drugs have become popular therapies. Since the treatment with plant based drugs had been used thousand years ago, they are thought to be relatively safe and effective drugs [37]. The literature notes [36] that calycosin from Chinese Angelica (Angelica sinensis) is a form of complement hematinic false drug. Therefore, we estimated the calycosin content of potential compounds. The structure of calycosin is shown in Figure 2.
Figure 3 shows the interactions of the top compound between ligand and residues in binding site. Calycosin has $\pi$ interaction with Gln158, hydrogen bonds with Glu144, Gln147, and Ala160, polarity force with Asn110, Glu144, Gln147, Gln158, and Ala160, and van der Waals force with Phe142, Pro145, Cys157, and Leu159. The stability of calycosin is maintained by the pi interaction, hydrogen bond, polarity, and van der Waals force (Figure 3). Figure 4 shows the hydrophobic contacts between candidate compound and amino acids in the binding site. Calycosin has hydrophobic 


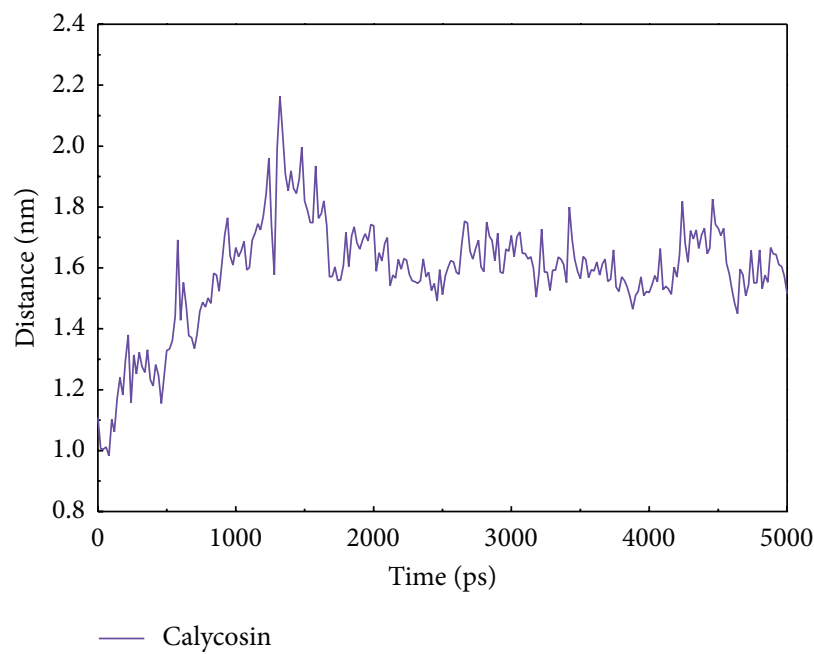

FIGURE 10: Distance trend between mass centers of protein and calycosin.

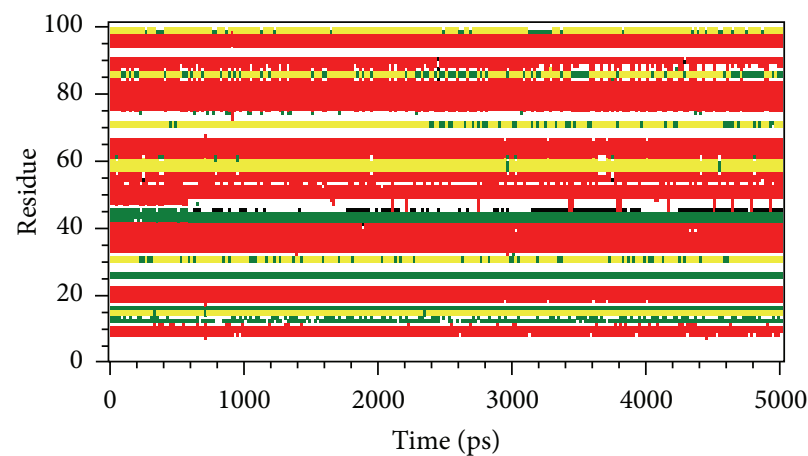

(a)

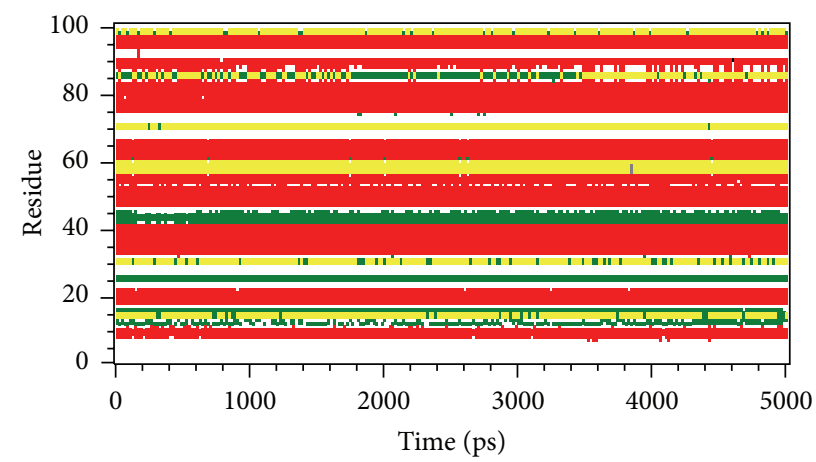

(b)

FIGURE 11: DSSP analysis of (a) protein complex with calycosin and (b) apoprotein.

contacts with three amino acids, Glu144, Gln158, and Leu159.

According to the docking results in Table 1, calycosin has potent binding affinity with target protein. Due to the results in Table 1, Glu144, Gln147, and Ala160 are important amino acids for binding.

3.2. Molecular Dynamics (MD) Simulation. Figure 5 shows the variation of root-mean-squared deviation (RMSD) for protein complexes with candidate compound and apoprotein in the process of molecular dynamics. For protein RMSD, it indicates the changes of IL6R protein structure for apoprotein and protein complexes with candidate compound. The variation of protein RMSD for apoprotein is more stable than protein complexes with candidate compound during MD simulation. For ligand RMSD, the values of RMSD for candidate compound tend to approximately $0.10-0.15 \mathrm{~nm}$. Figure 6(a) shows that protein complexes with calycosin had lower gyrate scores than the apoprotein, which indicated that the protein combined with calycosin is more stable than apoprotein. As shown by the slope of MSD in Figure 6(b), the protein combined with calycosin has higher diffusion changes than apoprotein as the slope is increasing after $2 \mathrm{~ns}$, which may have an influence on the protein displacement status. The total energy of protein complexes with candidate compound and apoprotein over $5000 \mathrm{~ns} \mathrm{MD}$ is located between -367000 and -36000 . There is no significant difference between protein complexes with candidate compound and apoprotein (Figure 7). The value of RMSF illustrates the flexibility of each amino acid in a time period of MD simulation. Figure 8 indicates that the important amino acids Glu144, Gln147, and Ala160 in protein complexes with calycosin are more stable. The clustering analysis can display the representative conformation of protein complexes with calycosin (cutoff of $0.142 \mathrm{~nm}$ ) (Figure $9(\mathrm{a})$ ) and apoprotein (cutoff of $0.145 \mathrm{~nm}$ ) (Figure 9(b)). Figure 10 illustrates the variation of distances between the mass centers of protein and calycosin. It shows that the binding of calycosin is not stable at initial, but it tends to stable after $2000 \mathrm{ps}$. The structure of DSSP (Figure 11) and the variation of Mdmat distribution (Figure 12) have no significant difference between protein complexes with calycosin and apoprotein. Figure 13 displays the eigenvector distribution for protein complexes with calycosin and apoprotein. Due to a combination of calycosin, 


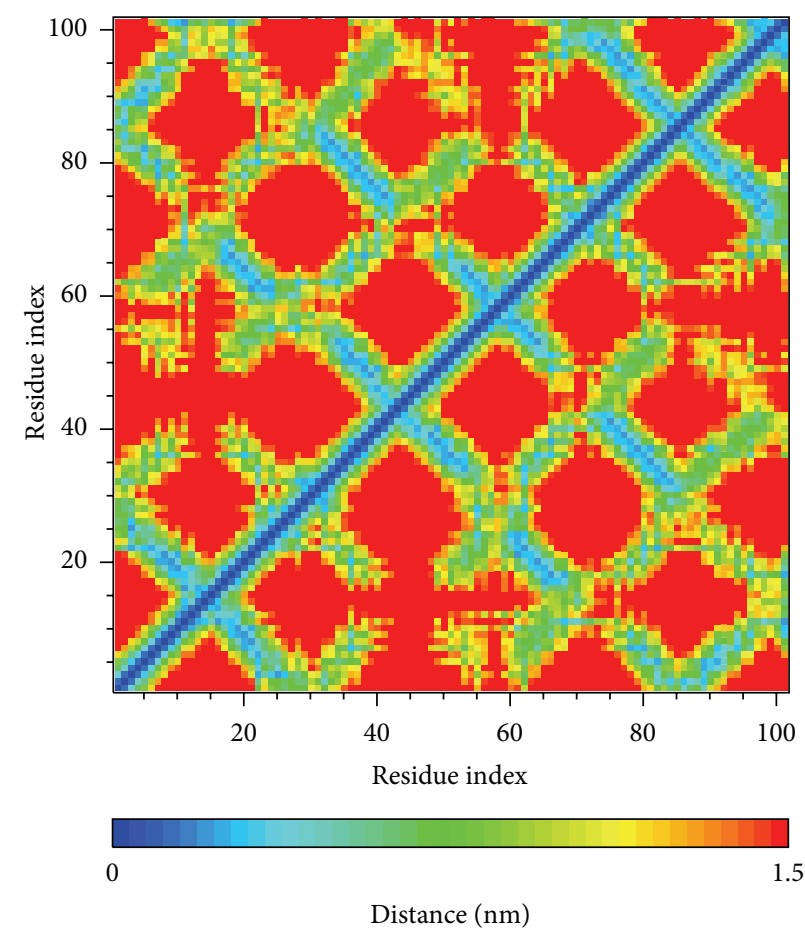

(a)

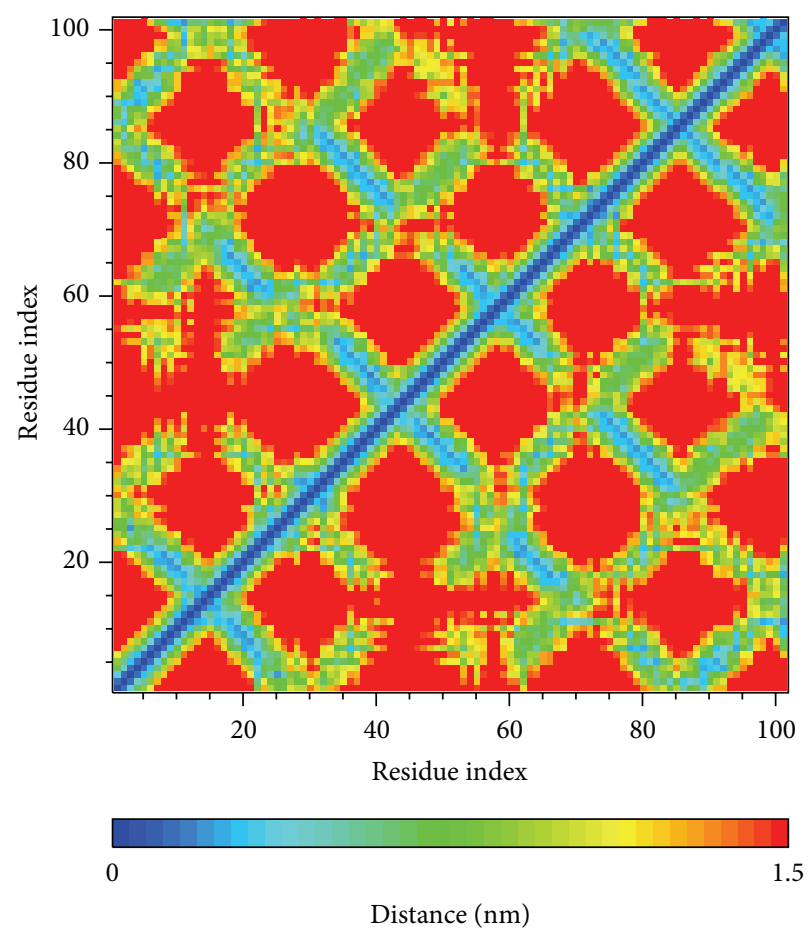

(b)

Figure 12: Mdmat analysis of (a) protein complex with calycosin and (b) apoprotein.

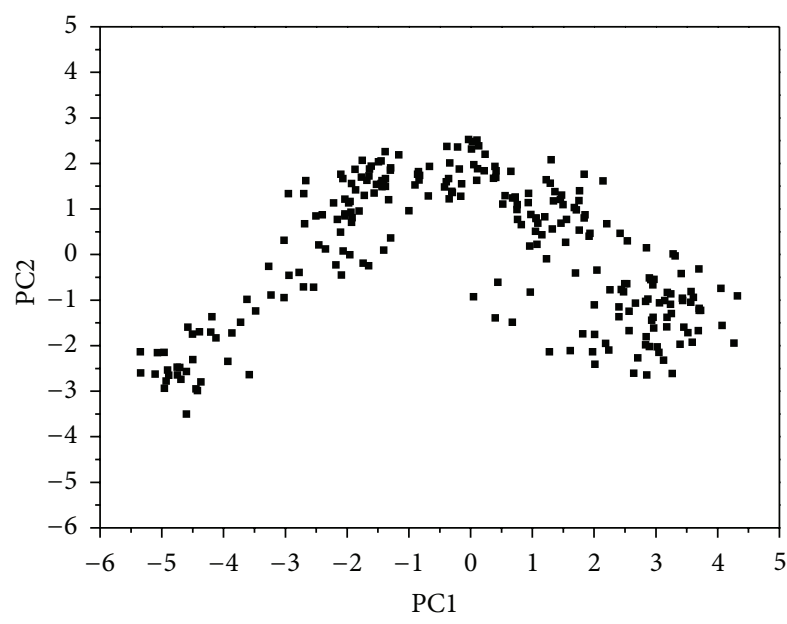

(a)

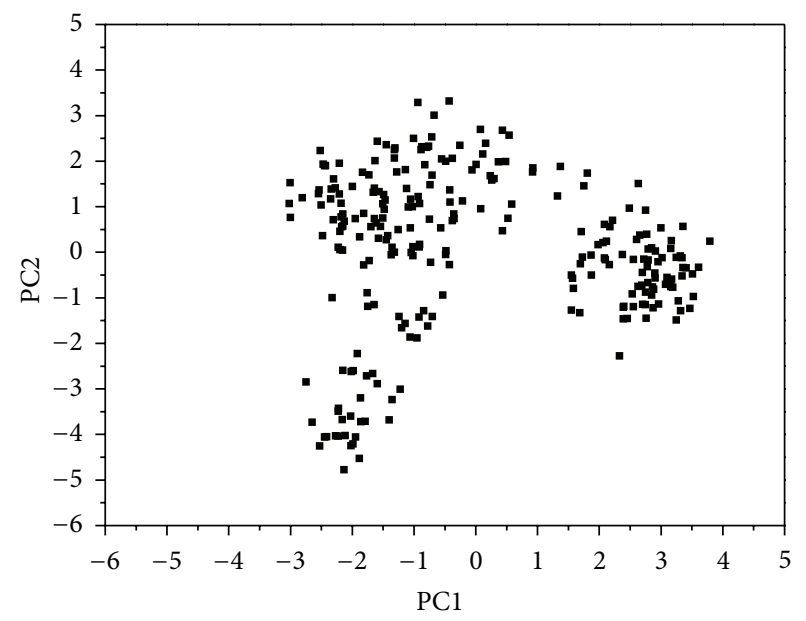

(b)

FIGURE 13: Eigenvector distribution of (a) protein complex with calycosin and (b) apoprotein.

the distribution of eigenvector $\mathrm{PCl}$ has expanded from -2 to -5 , and eigenvector PC2 has contracted from -5 to -2 , which indicates that there are some changes in the protein structure after combination. In addition, Figure 14 shows the distribution of eigenvectors PC1, PC2 and also illustrated the variation in the distribution of eigenvectors $\mathrm{PC} 1, \mathrm{PC} 2$. The results of transport pathway analysis shown in Figure 15 indicate the presumable pathway of small molecules with colors for protein complexes with calycosin and apoprotein. Protein complex with calycosin has less potential pathway than apoprotein, which indicates that the space of binding domain has variate after a combination of calycosin.

\section{Conclusion}

In this study, we employed the TCM database for virtual screening and ranking the results by the scoring function of Dock score, -PLP1, -PLP2, and H-bond forming residues, $\mathrm{H}$ bond quantity, and Pi forming residues. The influence of top candidate, calycosin, was investigated using apoprotein as the 

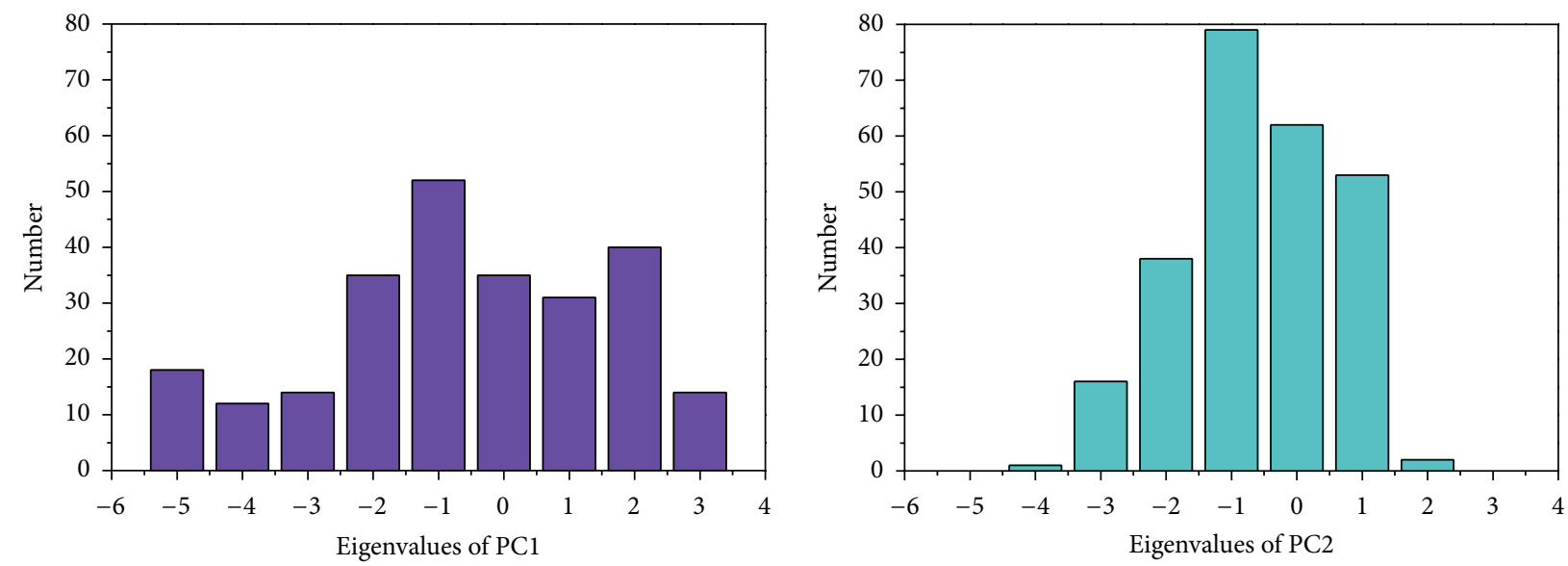

(a)
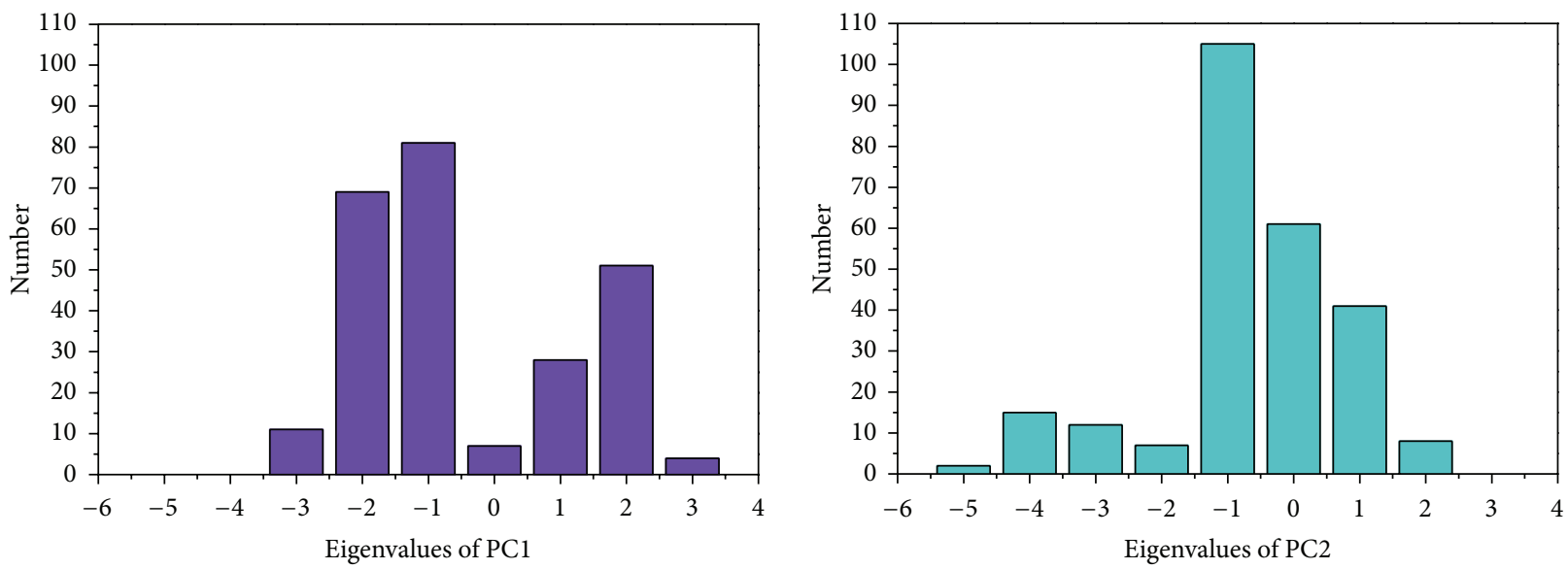

(b)

FIgURE 14: Analysis of eigenvectors PC1 and PC2 for (a) protein complex with calycosin and (b) apoprotein.

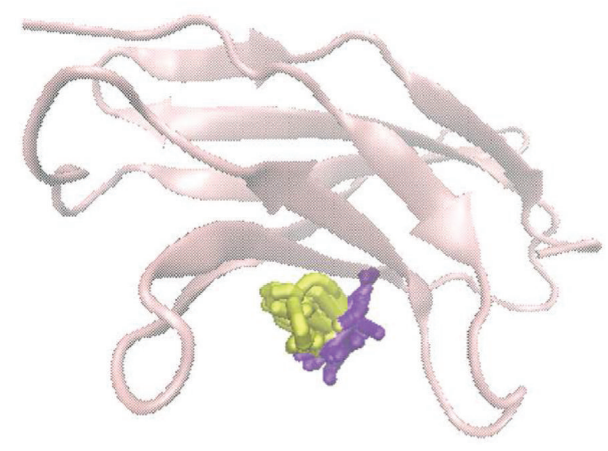

(a)

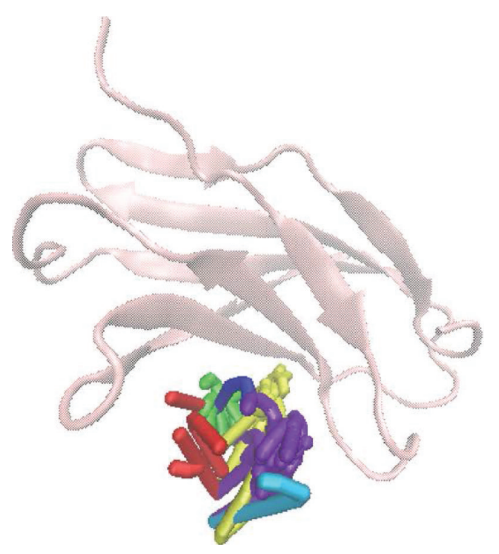

(b)

FIGURE 15: Analysis of transport pathways for (a) protein complex with calycosin and (b) apoprotein. 
control. After MD simulation, the analysis of RMSD, Gyrate, MSD, total energy, RMSF, cluster, distance of mass centers between protein and calycosin, DSSP, Mdmat, eigenvector, and analysis of transport pathway are performed for investigating the influence of calycosin binding in the receptor. Although there is only slight change in the protein structure, the analysis indicates that protein complex with calycosin is more stable than the apoprotein and the space of binding domain has decreased after a combination of calycosin as there are fewer pathways than apoprotein. Calycosin is known to be one of the components of Angelica sinensis, which has been indicated to have an important role in the treatment of rheumatoid arthritis. Therefore, we speculate that calycosin is a potential candidate as lead compounds for further study in drug development process with IL6R protein against rheumatoid arthritis.

\section{Conflict of Interests}

The authors confirm that this paper's content has no conflict of interests.

\section{Authors' Contribution}

Wen-Yuan Lee, Hsin-Yi Chen, and Kuan-Chung Chen equally contributed to the paper.

\section{Acknowledgments}

The research was supported by Grants from the National Science Council of Taiwan (NSC102-2325-B039-001 and NSC102-2221-E-468-027-), Asia University (ASIA100-CMU2, ASIA101-CMU-2, and 102-ASIA-07), and China Medical University Hospital (DMR-103-058, DMR-103-001, and DMR-103-096). This study is also supported in part by Taiwan Department of Health Clinical Trial and Research Center of Excellence (DOH102-TD-B-111-004) and Taiwan Department of Health Cancer Research Center of Excellence (MOHW103TD-B-111-03), and CMU under the Aim for Top University Plan of the Ministry of Education, Taiwan. Our gratitude goes to Tim Williams, Asia University.

\section{References}

[1] D. L. Scott, F. Wolfe, and T. W. J. Huizinga, "Rheumatoid arthritis," The Lancet, vol. 376, no. 9746, pp. 1094-1108, 2010.

[2] F. Wolfe, D. M. Mitchell, J. T. Sibley et al., "The mortality of rheumatoid arthritis," Arthritis and Rheumatism, vol. 37, no. 4, pp. 481-494, 1994.

[3] J. A. Aviña-Zubieta, H. K. Choi, M. Sadatsafavi, M. Etminan, J. M. Esdaile, and D. Lacaille, "Risk of cardiovascular mortality in patients with rheumatoid arthritis: a meta-analysis of observational studies," Arthritis Care and Research, vol. 59, no. 12, pp. 1690-1697, 2008.

[4] A. Gupta and B. Fomberstein, "Evaluating cardiovascular risk in rheumatoid arthritis," Journal of Musculoskeletal Medicine, vol. 26, no. 8, pp. 481-494, 2009.

[5] S. P. Mahamuni, R. D. Khose, F. Menaa, and S. L. Badole, "Therapeutic approaches to drug targets in hyperlipidemia," BioMedicine, vol. 2, no. 4, pp. 137-146, 2012.
[6] I.-C. Chou, W.-D. Lin, C.-H. Wang et al., "Association analysis between Tourette's syndrome and two dopamine genes (DAT1, DBH) in Taiwanese children," BioMedicine, vol. 3, no. 2, pp. 8891, 2013.

[7] T. Yamamoto, W.-C. Hung, T. Takano, and A. Nishiyama, "Genetic nature and virulence of community-associated methicillinresistant Staphylococcus aureus," BioMedicine, vol. 3, no. 1, pp. 2-18, 2013.

[8] Y.-M. Chang, B. K. Velmurugan, W.-W. Kuo et al., "Inhibitory effect of alpinate Oxyphyllae fructus extracts on Ang II-induced cardiac pathological remodeling-related pathways in $\mathrm{H} 9 \mathrm{c} 2$ cardiomyoblast cells," BioMedicine, vol. 3, pp. 148-152, 2013.

[9] Y. M. Leung, K. L. Wong, S. W. Chen et al., "Down-regulation of voltage-gated $\mathrm{Ca}^{2+}$ channels in $\mathrm{Ca}^{2+}$ store-depleted rat insulinoma RINm5F cells," BioMedicine, vol. 3, no. 3, pp. 130-139, 2013.

[10] Y. Jiang, X. Li, W. Yang et al., "PKM2 regulates chromosome segregation and mitosis progression of tumor cells," Molecular Cell, vol. 53, no. 1, pp. 75-87, 2014.

[11] V. Janssens and J. Goris, "Protein phosphatase 2A: a highly regulated family of serine/threonine phosphatases implicated in cell growth and signalling," Biochemical Journal, vol. 353, no. 3, pp. 417-439, 2001.

[12] K.-P. Su, "Inflammation in psychopathology of depression: clinical, biological, and therapeutic implications," BioMedicine, vol. 2, no. 2, pp. 68-74, 2012.

[13] M. A. Leissring, E. Malito, S. Hedouin et al., "Designed inhibitors of insulin-degrading enzyme regulate the catabolism and activity of insulin," PLoS ONE, vol. 5, no. 5, Article ID e10504, 2010.

[14] C.-L. Jao, S.-L. Huang, and K.-C. Hsu, "Angiotensin I-converting enzyme inhibitory peptides: inhibition mode, bioavailability, and antihypertensive effects," BioMedicine, vol. 2, no. 4, pp. 130-136, 2012.

[15] M.-C. Lin, S.-Y. Tsai, F.-Y. Wang, F.-H. Liu, J.-N. Syu, and F.Y. Tang, "Leptin induces cell invasion and the upregulation of matrilysin in human colon cancer cells," BioMedicine, vol. 3, no. 4, pp. 174-180, 2013.

[16] Y. Okada, D. Wu, G. Trynka et al., "Genetics of rheumatoid arthritis contributes to biology and drug discovery," Nature, vol. 506, pp. 376-381, 2013.

[17] R. J. Moots, A. J. K. Östör, and J. D. Isaacs, "Will treatment of rheumatoid arthritis with an IL-6R inhibitor help facilitate the "age of remission"?" Expert Opinion on Investigational Drugs, vol. 18, no. 11, pp. 1687-1699, 2009.

[18] J. C. W. Edwards, G. Cambridge, and V. M. Abrahams, "Do self-perpetuating B lymphocytes drive human autoimmune disease?" Immunology, vol. 97, no. 2, pp. 188-196, 1999.

[19] R. M. Plenge, M. Seielstad, L. Padyukov et al., "TRAF1-C5 as a risk locus for rheumatoid arthritis-a genomewide study," The New England Journal of Medicine, vol. 357, no. 12, pp. 1199-1209, 2007.

[20] I. Goeldner, T. L. Skare, I. T. de Messias Reason, R. M. Nisihara, M. B. Silva, and S. R. da Rosa Utiyama, "Anti-cyclic citrullinated peptide antibodies and rheumatoid factor in rheumatoid arthritis patients and relatives from Brazil," Rheumatology, vol. 49, no. 8, pp. 1590-1593, 2010.

[21] A. J. Silman, A. J. MacGregor, W. Thomson et al., "Twin concordance rates for rheumatoid arthritis: results from a nationwide study," British Journal of Rheumatology, vol. 32, no. 10, pp. 903-907, 1993. 
[22] N. Bellamy, D. Duffy, N. Martin, and J. Mathews, "Rheumatoid arthritis in twins: a study of aetiopathogenesis based on the Australian Twin Registry," Annals of the Rheumatic Diseases, vol. 51, no. 5, pp. 588-593, 1992.

[23] D. Sugiyama, K. Nishimura, K. Tamaki et al., "Impact of smoking as a risk factor for developing rheumatoid arthritis: a metaanalysis of observational studies," Annals of the Rheumatic Diseases, vol. 69, no. 1, pp. 70-81, 2010.

[24] K. P. Liao, L. Alfredsson, and E. W. Karlson, "Environmental influences on risk for rheumatoid arthritis," Current Opinion in Rheumatology, vol. 21, no. 3, pp. 279-283, 2009.

[25] H. Wen and J. F. Baker, "Vitamin D, immunoregulation, and rheumatoid arthritis," Journal of Clinical Rheumatology, vol. 17, no. 2, pp. 102-107, 2011.

[26] "Rheumatoid Arthritis Patients Have Double the Risk of Heart Failure," Science News, 2005, http://www.mayoclinic.org/.

[27] Cardiac Disease in Rheumatoid Arthritis, John Hopkins University, 2002.

[28] D.-Y. Lin, F.-J. Tsai, C.-H. Tsai, and C.-Y. Huang, "Mechanisms governing the protective effect of $17 \beta$-estradiol and estrogen receptors against cardiomyocyte injury," BioMedicine, vol. 1, no. 1, pp. 21-28, 2011.

[29] W.-L. Liao and F.-J. Tsai, "Personalized medicine: a paradigm shift in healthcare," BioMedicine, vol. 3, no. 2, pp. 66-72, 2013.

[30] C.-C. Lee, C.-H. Tsai, L. Wan et al., "Increased incidence of Parkinsonism among Chinese with $\beta$-glucosidase mutation in central Taiwan," BioMedicine, vol. 3, no. 2, pp. 92-94, 2013.

[31] I.-C. Chou, W.-D. Lin, C.-H. Wang et al., "Möbius syndrome in a male with XX/XY mosaicism," BioMedicine, vol. 3, no. 2, pp. 102-104, 2013.

[32] Y.-T. Chang, W.-D. Lin, Z.-N. Chin et al., "Nonketotic hyperglycinemia: a case report and brief review," BioMedicine, vol. 2, no. 2, pp. 80-82, 2012.

[33] C.-Y. Chen and C. Y.-C. Chen, "Insights into designing the dual-targeted HER2/HSP90 inhibitors," Journal of Molecular Graphics and Modelling, vol. 29, no. 1, pp. 21-31, 2010.

[34] S.-C. Yang, S.-S. Chang, H.-Y. Chen, and C. Y.-C. Chen, "Identification of potent EGFR inhibitors from TCM Database@ Taiwan," PLoS Computational Biology, vol. 7, no. 10, Article ID e1002189, 2011.

[35] Y.-A. Tsou, K.-C. Chen, H.-C. Lin, S.-S. Chang, and C. Y.-C. Chen, "Uroporphyrinogen decarboxylase as a potential target for specific components of traditional Chinese medicine: a virtual screening and molecular dynamics study," PLoS ONE, vol. 7, no. 11, Article ID e50087, 2012.

[36] K.-C. Chen, M.-F. Sun, S.-C. Yang et al., "Investigation into potent inflammation inhibitors from traditional Chinese medicine," Chemical Biology and Drug Design, vol. 78, no. 4, pp. 679688, 2011.

[37] K.-C. Chen and C. Yu-Chian Chen, "Stroke prevention by traditional Chinese medicine? A genetic algorithm, support vector machine and molecular dynamics approach," Soft Matter, vol. 7, no. 8, pp. 4001-4008, 2011.

[38] K.-C. Chen, K.-W. Chang, H.-Y. Chen, and C. Y.-C. Chen, “Traditional Chinese medicine, a solution for reducing dual stroke risk factors at once?" Molecular BioSystems, vol. 7, no. 9, pp. 2711-2719, 2011.

[39] T.-T. Chang, K.-C. Chen, K.-W. Chang et al., "In silico pharmacology suggests ginger extracts may reduce stroke risks," Molecular BioSystems, vol. 7, no. 9, pp. 2702-2710, 2011.
[40] W. I. Tou, S.-S. Chang, C.-C. Lee, and C. Y.-C. Chen, "Drug design for neuropathic pain regulation from traditional Chinese medicine," Scientific Reports, vol. 3, article 844, 2013.

[41] C. Y.-C. Chen, "A novel integrated framework and improved methodology of computer-aided drug design," Current Topics in Medicinal Chemistry, vol. 13, no. 9, pp. 965-988, 2013.

[42] C. Y.-C. Chen, “TCM Database@Taiwan: the world's largest traditional Chinese medicine database for drug screening In Silico," PLoS ONE, vol. 6, no. 1, Article ID e15939, 2011.

[43] J. N. Varghese, R. L. Moritz, M.-Z. Lou et al., "Structure of the extracellular domains of the human interleukin-6 receptor $\alpha$ chain," Proceedings of the National Academy of Sciences of the United States of America, vol. 99, no. 25, pp. 15959-15964, 2002.

[44] B. Xue, R. L. Dunbrack, R. W. Williams, A. K. Dunker, and V. N. Uversky, "PONDR-FIT: a meta-predictor of intrinsically disordered amino acids," Biochimica et Biophysica Acta-Proteins and Proteomics, vol. 1804, no. 4, pp. 996-1010, 2010.

[45] A. Ganesan, "The impact of natural products upon modern drug discovery," Current Opinion in Chemical Biology, vol. 12, no. 3, pp. 306-317, 2008.

[46] T. H. Keller, A. Pichota, and Z. Yin, "A practical view of 'druggability," Current Opinion in Chemical Biology, vol. 10, no. 4, pp. 357-361, 2006.

[47] M. T. H. Khan, "Predictions of the ADMET properties of candidate drug molecules utilizing different QSAR/QSPR modelling approaches," Current Drug Metabolism, vol. 11, no. 4, pp. 285295, 2010.

[48] B. R. Brooks, C. L. Brooks III, A. D. Mackerell Jr. et al., "CHARMM: the biomolecular simulation program," Journal of Computational Chemistry, vol. 30, no. 10, pp. 1545-1614, 2009.

[49] B. Hess, C. Kutzner, D. van der Spoel, and E. Lindahl, "GRGMACS 4: algorithms for highly efficient, load-balanced, and scalable molecular simulation," Journal of Chemical Theory and Computation, vol. 4, no. 3, pp. 435-447, 2008.

[50] V. N. Maiorov and G. M. Crippen, "Size-independent comparison of protein three-dimensional structures," Proteins: Structure, Function and Genetics, vol. 22, no. 3, pp. 273-283, 1995.

[51] E. Chovancova, A. Pavelka, P. Benes et al., "CAVER 3.0: a tool for the analysis of transport pathways in dynamic protein structures," PLoS Computational Biology, vol. 8, no. 10, Article ID e1002708, 2012. 

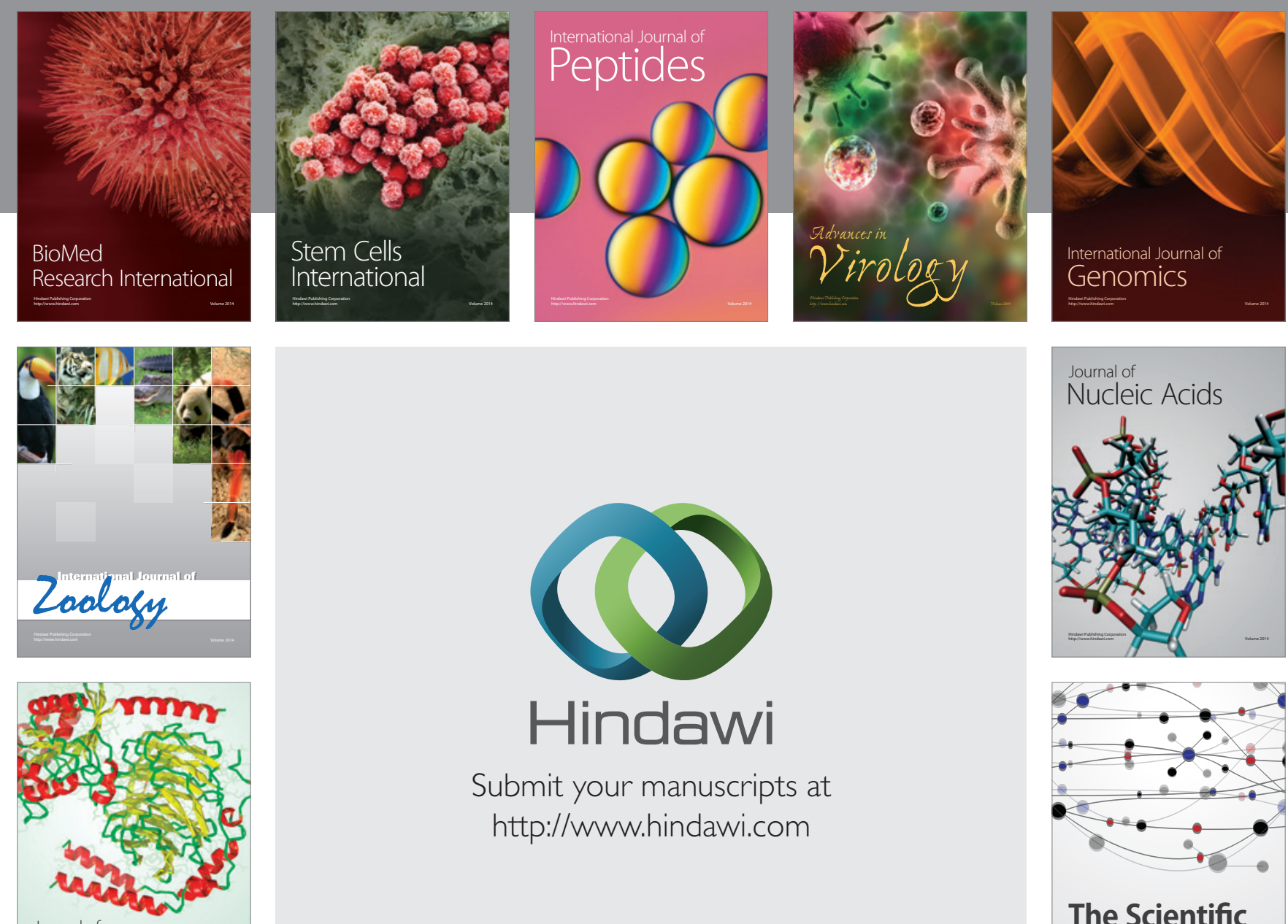

Submit your manuscripts at

http://www.hindawi.com

Journal of
Signal Transduction
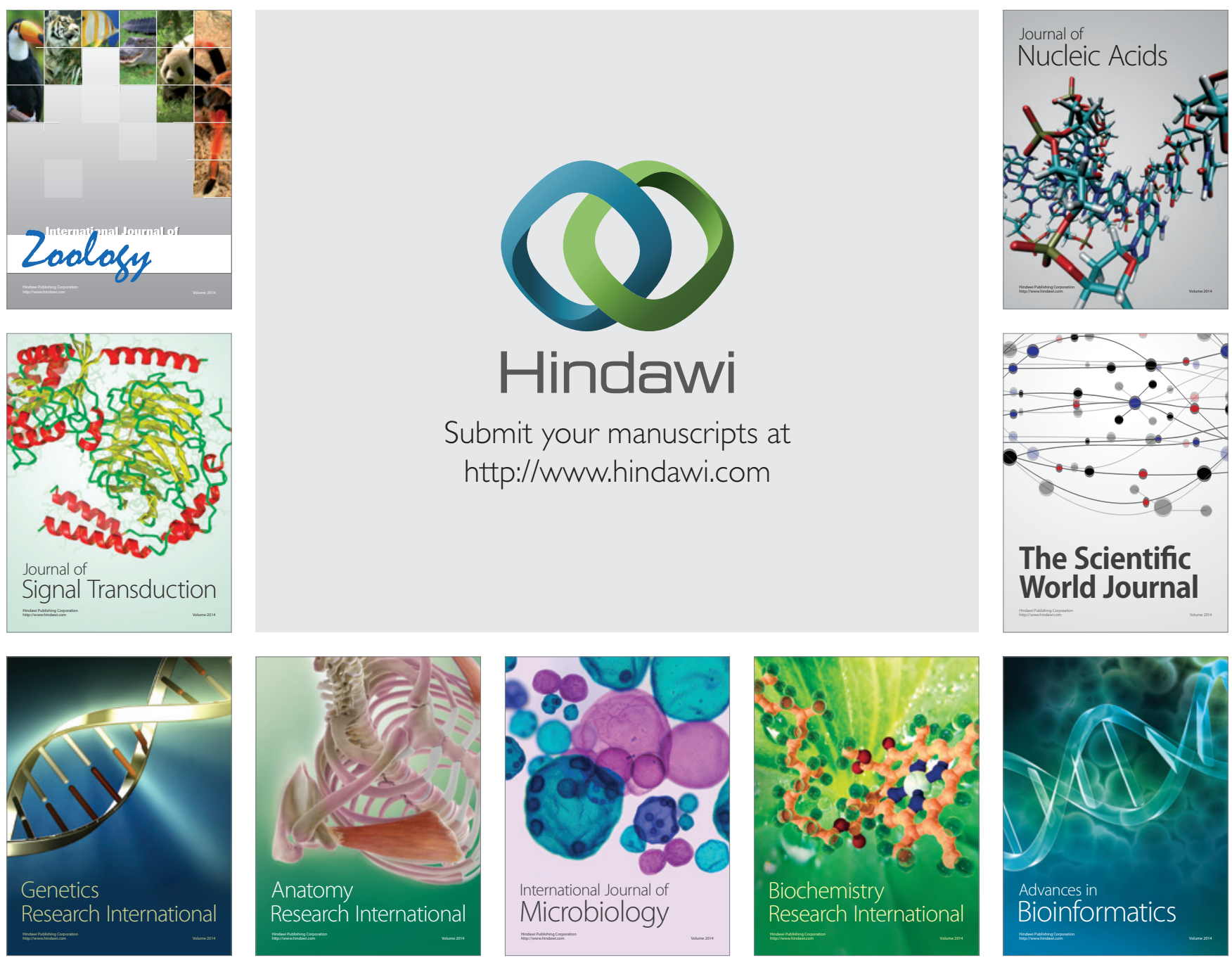

The Scientific World Journal
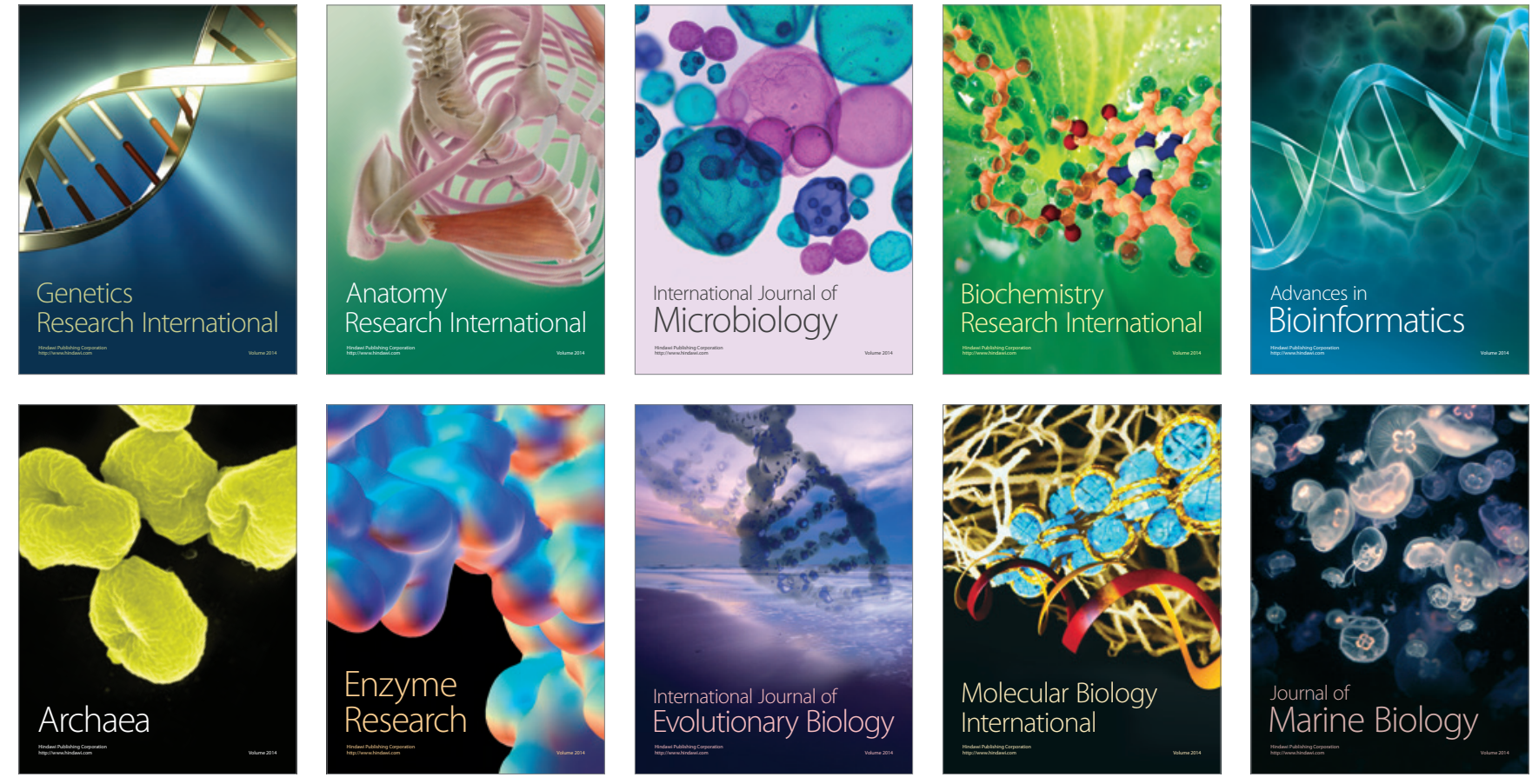